\title{
Potential Resistance of Employees to Change in the Transition to Industry $\mathbf{5 . 0}$
}

\author{
Gina-Maria Moraru, ${ }^{1, *}$, and Daniela Popa $^{1}$ \\ 1,'Lucian Blaga" University of Sibiu, Engineering Faculty, Industrial Engineering and Management \\ Department, Emil Cioran Street, No. 4, 550025 Sibiu, Romania
}

\begin{abstract}
The unprecedented evolution of the technological environment inevitably generates resistance to change in the population. The paper aims to detect these resistances in the conditions of a future transition to Industry 5.0. Firstly, we present the results of a bibliographic study of the specialized literature, in order to answer the dilemma of the existence or absence of the differences between the two concepts, that of Industry 4.0 and that of Industry 5.0. Secondly, the paper contains the results of an online survey based on a questionnaire conducted among employees in the central area of Romania. The research is related to the employees' perception on the possible evolution of the economic environment by implementing the concept of Industry 5.0. and focuses on issues that may bother them in their professional lives. Although we found that there are many oppositions to a potential transition to Industry 5.0, we still appreciate that the accelerated evolution of technology will be able to reduce much of them, the speed of technological change being much higher than the reaction speed of employees.
\end{abstract}

\section{Introduction}

The specialty literature shows that the goal of Industry 4.0 is "to increase productivity and achieve mass production using innovative technology" [1]. The fourth industrial revolution was triggered by the development of Information and Communication Technologies (ICT), and the main consequence of the ICT use is the reorganization of classical production system into a "self-organizing cyber physical production system that allows flexible mass custom production and flexibility in production quantity" [2]. The implementation of Industry 4.0 is needed to improve businesses in effectiveness and cost-efficiency and to transform the production system into an agile and customer-centric one [3]. There are many new areas and technologies that support Industry 4.0 on its way to smart manufacturing: the internet of things, artificial intelligence, cloud computing, virtual and augmented reality, robotics, 3D printing, smart logistics and so on [1]. The merging of several such technologies within a company is possible by using a single integrated network to collect and analyze data and to evaluate the development and performance of the company [4].

Industry 5.0 is taking another big step forward, placing "the wellbeing of the worker at the centre of the production process" and using new technologies to deliver "prosperity

*Corresponding author: gina.moraru@ulbsibiu.ro 
beyond jobs and growth while respecting the production limits of the planet" [5]. Even according to specialists - "Industry 4.0 implies the digitization of manufacturing via connected networks of humans and robots interacting and working together and promotes information sharing and analysis along the full global value chains" [6], Industry 5.0 raises the issue of human-robot co-working from a new perspective. This perspective revolves around bioeconomy [1], but it also puts research and innovation in support of the wellbeing of human resources [5]. If Industry 4.0 is focused on automation, Industry 5.0 will bring a synergy between humans and autonomous machines, and "will create more jobs than it will take away" [7]. The specialists conclude that Industry 5.0 needs the integration of artificial intelligence, found in three major elements - "intelligent devices, intelligent systems, and intelligent automation" - with human intelligence [7].

\section{Methodology of the research}

At the beginning of 2021, we have planed and started an online survey based on a questionnaire conducted among employees in the central area of Romania. The aim of the research was to discover the possibility of the fifth industrial revolution bothering our respondents in their professional lives. The characteristics of the 150 respondents from the central area of Romania are presented in Figure 1.

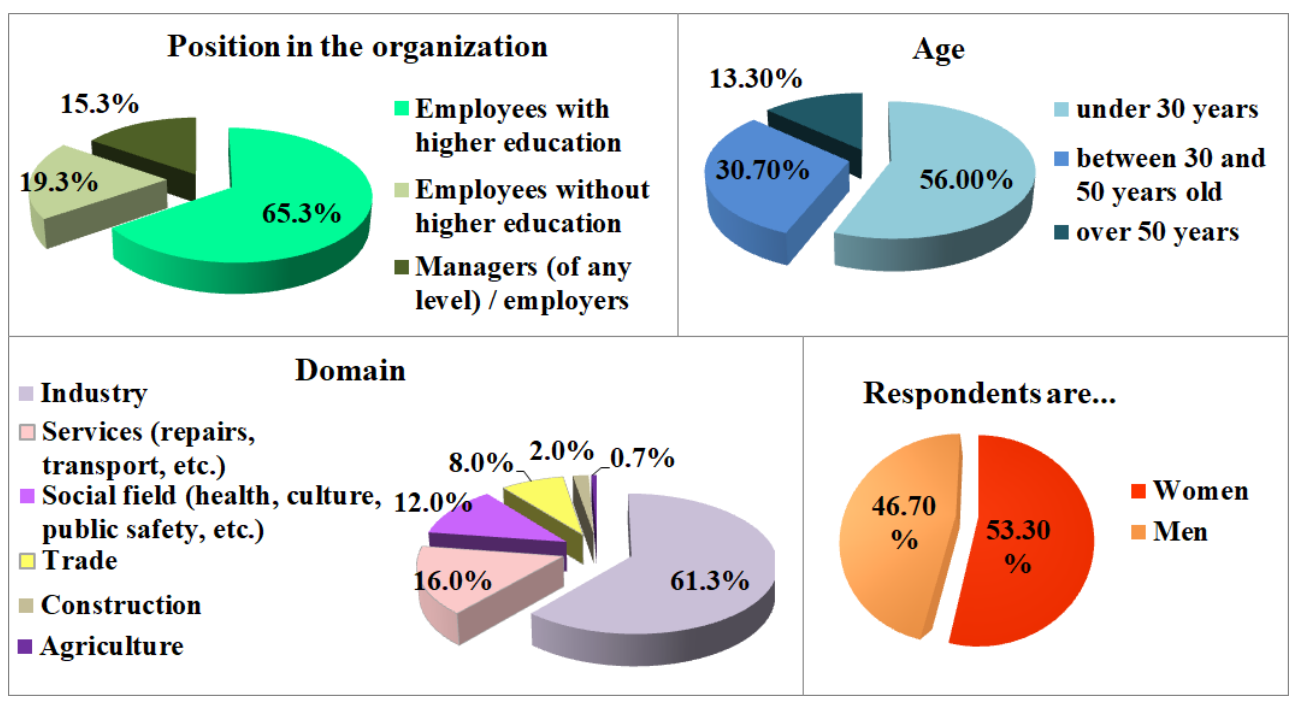

Fig. 1. Characteristics of respondents.

The questionnaire was based on questions with predefined answers and was pre-tested for 3 days on a group of 15 people, making the necessary corrections before distributing it online. In order to be understood and completed by employees with different levels of training, the questionnaire did not include specialized terms. Therefore, the concepts of Industry 4.0 or 5.0 were not even mentioned.

\section{Results}

To the first question, respondents had to choose one of three variants of appreciation of the statement "Many specialists claim that we will work soon, especially in industry, in collaboration with specialized robots". The answers are presented in Figure 2. 


$$
\begin{aligned}
& \text { "Many specialists } \\
& \text { claim that we will } \\
& \text { work soon, } \\
& \text { especially in } \\
& \text { industry, in } \\
& \text { collaboration with } \\
& \text { specialized robots." }
\end{aligned}
$$

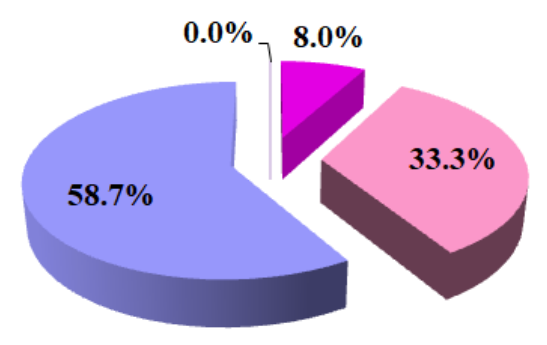

\section{Opinions of the respondents:}

- With the situation in our country, I do not think this will happen soon.

Large companies will probably implement this system in a few years.

- There is a good chance that working in human-robot collaboration will become a reality in many fields.

\section{I do not know.}

Fig. 2. Evaluation of the specialists' opinion by the respondents.

In order to calculate several statistics parameters, we have given the answer variants scores in an order proportional to the optimism related to a possible implementation of human-robot collaboration in all fields, as follows:

- 1 point for the answer "I do not know";

- 2 points for "With the situation in our country, I do not think this will happen soon";

- 3 points for "Large companies will probably implement this system in a few years";

- 4 points for "There is a good chance that working in human-robot collaboration will become a reality in many fields".

The mean of responses is 3.510, variance is 0.413 and standard deviation is 0.642 . Taking into account that the homogeneity coefficient is 0.183 , we conclude that the mean is representative for our sample and its value of 3.510 on a scale from 1 to 4 shows a lot of optimism. However, this is partly due to the fact that the sample was made up of $56 \%$ young adults under 30 years of age (Fig. 1).

The next question tried to determine the respondents' opinion about how they themselves, their colleagues, their superiors or the company's customers might be disturbed by the future human-robot collaboration. We have evaluated these variables from pessimistic perspective, using the scale: 1 point for "really pleased", 2 points for "not at all bothered", 3 points for "a little reluctant", and 4 points for "very upset". The statistical indicators are presented in Table 1, and the frequencies of the answer variants in Figure 3.

Table 1. How different stakeholders might be bothered by human-robot collaboration.

\begin{tabular}{|c|c|c|c|c|}
\hline $\begin{array}{c}\text { Person(s) assessed } \\
\text { by the respondent }\end{array}$ & Mean & Variance & $\begin{array}{c}\text { Standard } \\
\text { deviation }\end{array}$ & $\begin{array}{c}\text { Homogeneity } \\
\text { coefficient }\end{array}$ \\
\hline Colleagues & 2.573 & 0.568 & 0.754 & 0.293 \\
\hline Bosses & 1.947 & 0.695 & 0.834 & 0.428 \\
\hline $\begin{array}{c}\text { She herself/ he } \\
\text { himself }\end{array}$ & 1.973 & 0.697 & 0.835 & 0.423 \\
\hline Customers & 1.987 & 0.711 & 0.843 & 0.425 \\
\hline
\end{tabular}




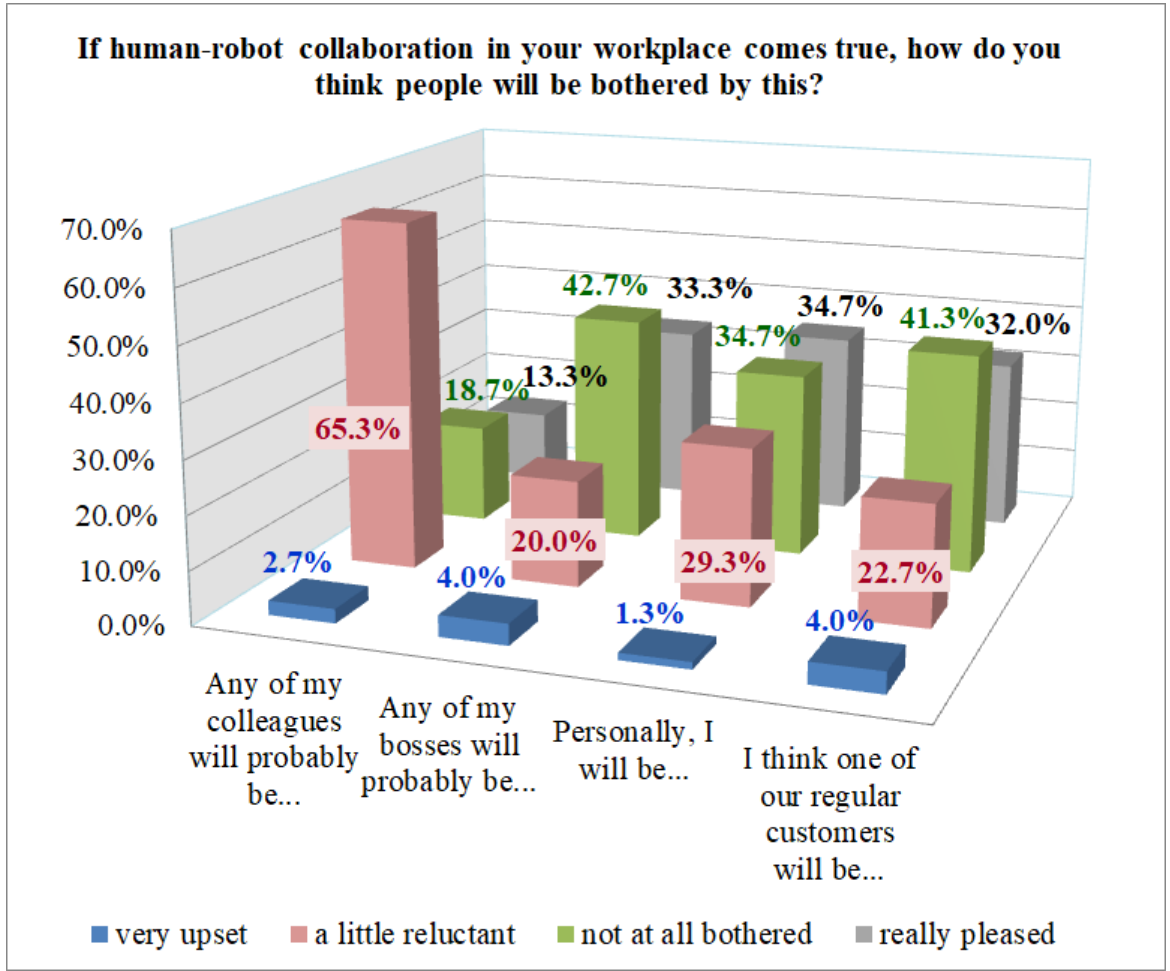

Fig. 3. Respondents' opinion about how they themselves, their colleagues, their superiors or the company's customers might be disturbed by the future robot-human collaboration.

Even if the answers registered a good degree of homogeneity only in the appreciation of the opinions of colleagues, we must still note the positioning of all means around 2 . These values indicate that, on the whole, the people in the respondents' organizations would not be bothered at all by the human-robot collaboration.

An important point of the questionnaire was the one in which the respondents were asked to evaluate some statements related to people's fears regarding human-cobot work, statements deduced from the study of literature [1, 5, 7]. Respondents' opinions are presented in Figure 4 and statistical indicators in Table 2.

We have to mention that the evaluation scale gave this time higher marks to the pessimistic answer variants and lower marks to the optimistic ones. Therefore, taking into account that the chosen statements represent possible negative events, the evaluation scale was: 1 point for "I do not know", 2 points for "no way", 3 points for "too little probably", and 4 points for "most probably".

Looking at means, we can conclude that all five statements mention potential dangers to the respondents, according to their perceptions, of course (Tab. 2). The most important danger that can lead to people's resistance to the next wave of technological change is the fear of losing their jobs (mean 3.613).

Another element which placed second according to the results of our research and which can cause resistance to change is a material factor. Namely, we are talking about the already existing difference between the salaries of employees in IT departments and those in production, maintenance, logistics, marketing or other departments of organizations (mean 3.573). This is valid in many fields of activity (especially in industry). We appreciate that a large part of our respondents could be negatively affected by the fact that the pay gap between IT and other fields will increase (Tab. 2). 
Table 2. Statements evaluated by respondents - statistical indicators.

\begin{tabular}{|c|c|c|c|c|}
\hline Statement & Mean & Variance & $\begin{array}{c}\text { Standard } \\
\text { deviation }\end{array}$ & $\begin{array}{c}\text { Homogeneity } \\
\text { coefficient }\end{array}$ \\
\hline Many people will lose their jobs. & 3.613 & 0.266 & 0.515 & 0.143 \\
\hline $\begin{array}{c}\text { There will be a competition between } \\
\text { man and robot for better positions. }\end{array}$ & 3.240 & 0.533 & 0.730 & 0.255 \\
\hline $\begin{array}{c}\text { Cobots will tend to dominate humans. } \\
\text { The pay gap between IT and other } \\
\text { fields will increase. }\end{array}$ & 2.760 & 0.613 & 0.783 & 0.284 \\
\hline $\begin{array}{c}\text { Social protests / trade union } \\
\text { movements will intensify. }\end{array}$ & 3.200 & 0.859 & 0.927 & 0.327 \\
\hline
\end{tabular}

From the perspective of the employability of human resources, how do you assess the following situations in the case of the introduction of cobots in the economy?

Many people will lose their jobs

There will be a competition between man and robot for better positions

Cobots will tend to dominate humans

The pay gap between IT and other fields will increase

Social protests / trade union movements will intensify

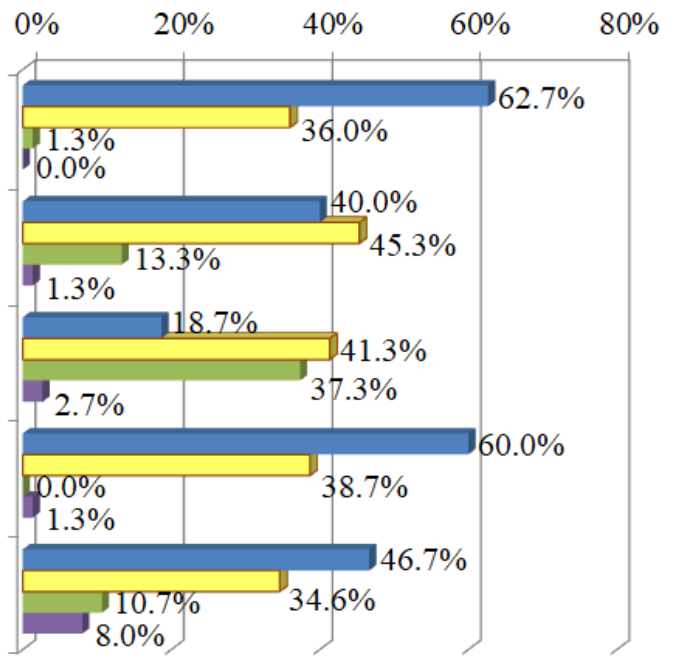

Most probably $\square$ Too little probably $\quad$ No way $\quad \square$ I do not know

Fig. 4. Possible negative effects on human resources.

Although it was not expected, the statement regarding the competition between humans and cobots for better positions in the organization also obtained a very high mean (3.240). On the one hand, we believe that young respondents are extremely competitive. On the other hand, all of our respondents - and therefore the young ones, too - are largely convinced that the fifth technological wave will take place (Fig. 1). This is how we can explain why many young people agreed with the statement about the human-cobot competition.

Regarding respondents over the age of 50, we believe that they have already faced situations in their professional lives that have confirmed that employment prospects of 
elderly workers are declining in Romania, an aspect highlighted by the literature for other European countries, too [8].

The intensification of social protests and trade union movements is a fact that respondents view as almost imminent (mean 3.200), and in the future it will remain a form of resistance to change representative of society.

Even if the statement "cobots will tend to dominate humans" has recorded only the mean 2.760, we consider that this opinion remains the cause of several potential resistances to the transition to Industry 5.0.

\section{Conclusions}

The research above was correlated to the employees' perception of the possible evolution of the economic environment by implementing the concept of Industry 5.0. and was focused on issues that might bother them in their professional lives. Most respondents have appreciated that there is a good chance that working in human-robot collaboration will become a reality in many fields. Just as reported by specialists from other countries $[1,7]$, we have found that in Romania there also exist a fear that employees will lose their jobs by robot replacement and compete with robots for better positions in organizations.

Although we discovered that there are many oppositions to a potential transition to Industry 5.0, we still appreciate that the accelerated evolution of technology will be able to reduce a lot of them, the speed of technological change being much higher than the reaction speed of employees.

One of our future researches will aim to detect the reactions of employees in case of a potential collaboration with a cobot meant to make their work easier. In this context, we will try to find out if the collaborating robots will be accepted only for routine activities or also for smarter activities. We are also concerned about a future study that seeks to find out whether working with cobots could increase human resource creativity, on the one hand, and whether it could influence the organization's results, on the other.

A vast field that future research must pursue is the issue of ethics in the organization and in society in the case of human-robot collaboration.

\section{References}

1. K.A. Demir, G. Döven, B. Sezen, Procedia Computer Science 158, 688-695 (2019)

2. A. Rojko, iJIM 11 (5), 77-90 (2017)

3. R. Miskiewicz, R. Wolniak, Sustainability 12, 5776 (2020)

4. J. Nagy, J. Oláh, E. Erdei, D. Máté, J. Popp, Sustainability 10, 3491 (2018)

5. European Commission, Industrial research and innovation. Industry 5.0, https://ec.europa.eu/info/research-and-innovation/research-area/industrial-research-andinnovation/industry-50_en (European Commission website, 2020)

6. L.M. Fonseca, Proceedings of the 12th International Conference on Business Excellence, 386397 (De Gruyter, 2018)

7. S. Nahavandi, Sustainability 11, 4371 (2019)

8. A. Walker, P. Taylor, Combating Age Barriers in Employment: A European Portofolio of Good Practice (European Foundation for the Improvement of Living and Working Conditions, Dublin, 1998) 